\title{
Hubungan Status Gizi dengan Kebugaran Jasmani Atlet Taekwondo Remaja
}

\author{
Isnanda Putri Nur Istiqomah ${ }^{\mathbf{1}}$, Agus Kristiyanto ${ }^{2}$, Tonang Dwi Ardyanto ${ }^{\mathbf{3}}$ \\ ${ }^{1,2,3}$ Sekolah Pascasarjana Universitas Sebelas Maret, Surakarta, Jawa Tengah \\ Email :1 $\underline{\text { isnandaputri3@gmail.com, }}{ }^{2}$ agus_k@staff.uns.ac.id ${ }^{3}$ tonang.ardyanto@ staff.uns.ac.id,
}

Tanggal Submisi : 7 Juni 2021 ; Tanggal Penerimaan: 18 Desember 2021

\begin{abstract}
ABSTRAK
Penelitian ini bertujuan untuk menganalisis hubungan antara status gizi dengan kebugaran jasmani atlet taekwondo remaja. Metode penelitian ini menggunakan desain cross sectional dengan jumlah sampel sebanyak 30 atlet taekwondo remaja, sampel diambil menggunakan metode secara acak sederhana yaitu simple random sampling. Pengumpulan data meliputi status gizi dengan cara pengambilan data antropometri berat badan dan tinggi badan, kebugaran jasmani dengan menggunakan tes lari MFT (multistage fitness). Analisis yang digunakan adalah analisis univariat dan bivariat menggunakan uji korelasi pearson product moment. Hasil penelitian menunjukkan terdapat hubungan antara status gizi dengan kebugaran jasmani $(\mathrm{p}=0,028)$. Nilai $\mathrm{R}$ sebesar $-0,401$ menunjukkan kekuatan hubungan yang sedang, nilai negatif menunjukkan hubungan yang terbalik pada variabel. Atlet yang memiliki status gizi yang baik cenderung memiliki kebugaran jasmani yang baik pula. Perlu dilakukan penambahan informasi terkait gizi pada atlet sehingga terciptanya status gizi baik serta kebugaran jasmani yang baik pada atlet. Kata Kunci: Kebugaran Jasmani, Status Gizi, Taekwondo
\end{abstract}

\section{ABSTRACK}

The purpose of this study was to analyze the relationship between nutritional status and physical fitness of adolescent taekwondo athletes. This study used a cross sectional design with a total sample of 30 teenage taekwondo athletes, the sample was taken using a simple randomized method, namely simple random sampling. Data collection includes nutritional status by taking anthropometric data on body weight and height, physical fitness using the MFT (multistage fitness) running test. The analysis used was univariate and bivariate analysis using the Pearson product moment correlation test. The results showed that there was a relationship between nutritional status and physical fitness $(p=0.028)$. An $R$ value of -0.401 indicates a moderate relationship strength, a negative value indicates an inverse relationship to the variable.. Athletes who have good nutritional status tend to have good physical fitness as well. It is necessary to add information related to nutrition for athletes to create good nutritional status and good physical fitness for athletes.

Keywords: Physical Fitness, Nutritional Status, Taekwondo

ISSN 2722-9610

E - ISSN 2722-9629 


\section{PENDAHULUAN}

Taekwondo telah muncul sebagai seni bela diri internasional untuk pertahanan diri yang menggunakan tangan dan kaki terutama untuk pertahanan dan serangan. Sebagai olahraga, dari segi struktur temporal, pertandingan / pertarungan berlangsung selama tiga babak yang terdiri dari dua menit dengan waktu istirahat satu menit di antara setiap babak. Seperti kebanyakan olahraga tempur, ini dicirikan sebagai aktivitas berselang-seling asiklik, di mana pertarungan gerakan pendek dan intens (momen pertempuran) bergantian dengan periode intensitas rendah (Matsushigue et al, 2009).

Kebugaran jasmani merupakan kemampuan seseorang dalam melakukan tugasnya sehari tanpa mengalami kelelahan (Widiastuti, 2015). Kebugaran jasmani merupakan salah satu hal terpenting terutama bagi remaja karena aktivitasnya yang tinggi. Faktor-faktor yang mempengaruhi kebugaran jasmani seperti aktivitas fisik dan IMT / Usia (Kasyifa dkk, 2018). Asupan gizi yang inadekuat pada atlet saat latihan dan bertanding menyebabkan penurunan performa dan berisiko mengalami permasalahan kesehatan (Mountjoy et al., 2018). Latihan fisik yang terus-menerus menuntun atlet untuk mempertahankan keseimbangan yang tidak stabil antara asupan makanan, pengeluaran energi, dan tuntutan tambahan dari aktivitas fisik dalam jumlah besar. Dengan demikian, penilaian status gizi yang akurat sangat penting untuk mengoptimalkan kinerja, karena mempengaruhi kesehatan, komposisi tubuh, dan pemulihan atlet (Mielgo et al, 2015).

Kapasitas aerobik seorang atlit merupakan salah satu elemen penting dalam keberhasilan prestasi olahraga. Ini umumnya dianggap sebagai indikator terbaik dari daya tahan pernafasan kardio dan kebugaran atletik. Persentase lemak tubuh mempengaruhi
VO2 max dan dengan demikian status kardiovaskular para atlet (Shete et al, 2014).

\section{METODE}

Penelitian ini adalah penelitian observasional analitik dengan pendekatan cross sectional untuk mengetahui hubungan antara status gizi dengan kebugaran jasmani atlet taekwondo remaja. Pelaksanaan penelitian dilakukan pada bulan Maret 2021 di Klub taekwondo Mahameru Sukoharjo dengan jumlah sampel sebesar 30 atlet. Kriteia inklusi dalam pemilihan sampel antara lain atlet taekwondo usia 10-18 tahun, tidak mengalami cedera fisik, tidak absen latihan 5 kali berturut-turut dan bersedia ikut serta dalam penelitian ini.

Variabel bebas dalam penelitian ini adalah Status gizi sedangkan variable terikat adalah kebugaran jasmani. Status gizi diperoleh dengan cara pengukuran antropometri berat badan dan tinggi badan. Status gizi diukur berdasarkan $z$-score indeks massa tubuh terhadap umur (IMT/U), dengan kategori sebagai berikut:

Tabel 1.

Klasifikasi Indikator Status Gizi IMT/U

\begin{tabular}{lc}
\hline $\begin{array}{c}\text { Kategori status } \\
\text { gizi }\end{array}$ & $\begin{array}{c}\text { Ambang Batas } \\
\text { (Z-Score) }\end{array}$ \\
\hline Gizi Kurang & -3 SD sampai \\
& dengan <-2 SD \\
Gizi Baik & -2 SD sampai \\
& dengan + 1 SD \\
& +1 SD sampai \\
Gizi Lebih & dengan + 2 SD \\
& Lebih dari +2 SD \\
Obesitas & \\
\hline Sumber: & \\
(Permenkes, & \\
2020) &
\end{tabular}

Data kebugaran jasmani diperoleh dari tes lari Multistage Fitness (MFT), yaitu lari bolak balik dengan lintasan 20 meter, dengan kategori sebagai berikut: 
Tabel 2.

Kategori Kebugaran berdasarkan konsumsi oksigen $\mathrm{VO}_{2} \mathrm{Max}$

\begin{tabular}{lcc}
\hline \multirow{2}{*}{ Kategori } & \multicolumn{1}{c}{ VO $_{\text {Max }}$} & \\
\cline { 2 - 3 } & Laki-laki & Perempuan \\
\hline Sangat & $<43,40$ & $<39,10$ \\
buruk & & \\
buruk & $43,30-49,10$ & $39,20-44,10$ \\
cukup & $49,20-55,00$ & $44,20-49,20$ \\
Baik & $55,10-60,90$ & $49,30-54,20$ \\
Sangat & $>61,00$ & $>53,30$ \\
baik & & \\
\hline
\end{tabular}

(Sumber : Perkembangan Olahraga Terkini, Jakarta, 2003)

Analisis data pada penelitian ini menggunakan uji korelasi Pearson dengan uji kenormalan data menggunakan Kolmogorov Smirnov. Uji korelasi dilakukan untuk menganalisis hubungan antara status gizi dengan kebugaran jasmani pada atlet taekwondo remaja.

\section{HASIL DAN PEMBAHASAN}

Berdasarkan hasil penelitian diketahui karakteristik jenis kelamin pada atlet teaekwondo remaja yang ditampikan pada Tabel 3 menunjukkan bahwa laki laki sebesar $40 \%$ dan perempuan sebesar $60 \%$.

Berdasarkan tabel 3 menunjukkan bahwa atlet memiliki rentang usia 13-15 tahun paling banyak dibandingkan rentang usia yang lainnya, yaitu sebesar 50\%. Atlet usia 10-12 tahun sebanyak $16,7 \%$ dan responden usia 16-18 tahun sebesar 33,3\%. Sebagian besar atlet memiliki status gizi yang baik yaitu sebesar $80,0 \%$ dan kebugaran jasmani yang baik yaitu sebesar 53\%.

Tabel 3.

Distribusi Frekuensi karakteristik Atlet

\begin{tabular}{lll}
\multicolumn{3}{c}{ Taekwondo Remaja } \\
\hline Karakteristik & $\mathbf{n}$ & \% \\
\hline Jenis kelamin & & \\
Laki-laki & 12 & 40,0 \\
Perempuan & 18 & 60,0 \\
\hline Total & 30 & 100,0 \\
\hline Usia & & \\
$10-12$ tahun & 5 & 16,7 \\
& & \\
13-15 tahun & 15 & 50,0 \\
$16-18$ tahun & 10 & 33,3 \\
\hline Total & 30 & 100,0 \\
\hline Status Gizi & & \\
Gizi Kurang & 2 & 6,7 \\
Gizi Baik & 24 & 80,0 \\
Gizi Lebih & 2 & 6,7 \\
Obesitas & 2 & 6,7 \\
\hline Total & 30 & 100,0 \\
\hline Kebugaran jasmand
\end{tabular}

Kebugaran jasmani

\begin{tabular}{lll} 
Kurang sekali & 0 & 0,0 \\
Kurang & 1 & 3,3 \\
Sedang & 7 & 23,3 \\
Baik & 16 & 53,3 \\
Baik sekali & 6 & 20,2 \\
\hline
\end{tabular}

Total 30

Sumber : Data Primer (2021)

Tabel 4. 


\section{Hasil Tabulasi Silang Status Gizi dengan Kebugaran Jasmani}

\begin{tabular}{|c|c|c|c|c|c|c|c|c|c|c|}
\hline \multirow{3}{*}{ Status gizi } & \multicolumn{5}{|c|}{ Kebugaran } & \multicolumn{3}{|c|}{ Jasmani } & \multirow[b]{2}{*}{$\begin{array}{c}\mathrm{P} \\
\text { value }\end{array}$} & \multirow{3}{*}{ Nilai $r$} \\
\hline & \multicolumn{2}{|c|}{ kurang } & \multicolumn{2}{|c|}{ sedang } & \multicolumn{2}{|c|}{ baik } & \multicolumn{2}{|c|}{$\begin{array}{c}\text { Baik } \\
\text { sekali }\end{array}$} & & \\
\hline & $\mathrm{N}$ & $\%$ & $\mathrm{~N}$ & $\%$ & $\mathrm{~N}$ & $\%$ & $\mathrm{~N}$ & $\%$ & & \\
\hline Kurang & 0 & 0,0 & 0 & 0,0 & 2 & 6,7 & 0 & 0,0 & 0,028 & $\begin{array}{c}- \\
0,401\end{array}$ \\
\hline Normal & 0 & 0,0 & 6 & 20,0 & 12 & 40,0 & 6 & 20,0 & & \\
\hline Lebih & 0 & 0,0 & 0 & 0,0 & 2 & 6,7 & 0 & 0,0 & & \\
\hline Obesitas & 1 & 3,3 & 1 & 3,3 & 0 & 0,0 & 0 & 0,0 & & \\
\hline Total & 1 & 3,3 & 7 & 23,3 & 16 & 53,3 & 6 & 20,0 & & \\
\hline
\end{tabular}

Sumber : Data Primer (2021)

Berdasarkan tabel 4 menunjukkan bahwa status gizi yang kurang cenderung memiliki kebugaran jasmani yang baik yaitu sebesar 6,7\%, status gizi normal cenderung memiliki kebugaran jasmani yang baik yaitu sebesar $40 \%$, status gizi lebih cenderung memiliki kebugaran jasmani yang baik yaitu sebesar $6,7 \%$ dan status gizi obesitas cenderung memilki kebugaran jasamani yang kurang yaitu sebesar 33\%.

Berdasarkan uji korelasi pearson, menunjukkan bahwa nilai $p=0,028(p<0,05)$ yang berarti bahwa terdapat hubungan antara status gizi dengan kebugaran jasmani. Derajat kekuatan hubungan ditunjukkan dengan nilai $r=$ -0,401 yang berarti kekuatan hubungan antar variabel adalah sedang, Jenis hubungan antar variabel adalah negatif.

\section{PEMBAHASAN}

Terdapat hubungan antara status gizi dengan kebugaran jasmani atlet taekwondo remaja, nilai $r$ negatif yang menunjukkan bahwa data berbanding terbalik sehingga jika status gizi meningkat maka kebugaran jasmaninya akan menurun. Hasil ini sejalan dengan penelitian Cornia (2018) yang menyatakan bahwa ada hubungan status gizi dengan kebugaran jasmani mahasiswa UKM Taekwondo. Penilaian status gizi mengukur dimensi tubuh dengan indeks berat badan terhadap tinggi badan $(\mathrm{BB} / \mathrm{TB})$.

Dimensi tubuh yang semakin besar atau obesitas dapat mempengaruhi gerak tubuh dalam melakukan aktivitas fisik menjadi kurang maksimal (Azizin, 2014).

Keberhasilan atlet dalam meraih prestasi salah satunya didukung oleh status gizinya (Hasanatun et al, 2019). Selain status gizi, kebugaran jasmani di pengaruhi juga oleh faktor asupan gizi. Menurut Fatmah (2011) derajat kesehatan dan kebugaran individu dipengaruhi oleh tiga faktor utama salah satunya yaitu pengaturan asupan makanan atau zat gizi. Hal ini sejalan menurut Depkes RI (2010) bahwa konsumsi energi dan zat gizi seimbang dapat memperbaiki status gizi, meningkatkan ketahanan fisik, serta meningkatkan produktivitas.

Status gizi merupakan keadaan tubuh sebagai akibat konsumsi makanan dan penggunaan zat-zat gizi dalam bentuk variabel tertentu yang dapat diukur dengan metodemetode tertentu. Status gizi yang rendah atau tidak normal akan memberikan dampak pada tingkat kebugaran jasmani (Hidayat dan Suroto, 
2017). Penelitian yang dilakukan oleh Cahyaputra (2016), menyatakan bahwa ada

hubungan positif dan signifikan antara pola makan dan status gizi dengan tingkat kebugaran jasmani pada siswa.

Kapasitas aerobik seorang atlet merupakan salah satu elemen penting dalam keberhasilan pencapaian prestasi olahraga. $\mathrm{VO}_{2} \max$ mengacu pada intensitas proses aerobik dan sebenarnya menunjukkan kapasitas maksimum untuk mengangkut dan memanfaatkan oksigen selama latihan yang dilakukan pada intensitas yang meningkat. $\mathrm{VO}_{2} \max$ adalah tingkat konsumsi oksigen tertinggi yang dapat dicapai selama latihan maksimal, ini mencerminkan kebugaran fisik seseorang yang memiliki kapasitas atletik (Rancovic et al, 2010). Kebugaran jasmani yang optimal dapat ditingkatkan dengan pemenuhan gizi yang cukup, istirahat yang cukup, olahraga yang teratur dan dengan menjaga kesehatan (Rismayanthi, 2012).

\section{KESIMPULAN}

Terdapat hubungan status gizi dengan kebugaran jasmani atlet taekwondo remaja dengan arah hubungan negatif, sehingga status gizi yang rendah maka kebugaran jasmaninya meningkat.

\section{SARAN}

Atlet disarankan untuk mengkonsumsi makanan yang sesuai dengan kebutuhan hariannya karena berpengaruh terhadap status gizi pada atlet. Atlet yang memiliki status gizi yang baik maka kebugarannya meningkat sehingga tercapai prestasi yang maksimal

\section{UCAPAN TERIMAKASIH}

Penulis mengucapkan terimakasih kepada pihak Klub Taekwondo Mahameru Sukoharjo yang telah memberikan izin kepada peneliti untuk melaksanakan penelitian dan membantu memperoleh data yang diperlukan. Terimakasih juga kepada para atlet taekwondo

yang telah bersedia menjadi responden dalam penelitian ini, serta semua pihak yang telah membantu dan memberikan dukungan sehingga terselesaikannya penelitian ini.

\section{REFERENSI}

Apor P 2011. [Measure of fitness and physical activity related to cardiovascular diseases and death]. Orv Hetil 152: 107-113.

Azizin I. 2014. Hubungan Status Gizi dan Aktivitas Fisik dengan Tingkat Kebugaran Jasmani Siswa Sekolah Dasar. Jurnal Kesehatan Olahraga.02 (02):17-22.

Cahyaputra, E. 2016. Hubungan Antara Pola Makan, Status Gizi, dan Tingkat Kebugaran Jasmani Siswa Kelas Atas SD Rejosari 3 Semin Gunung kidul. Pendidikan Jasmani Kesehatan Dan Rekreasi, 6(2), 135.

Fatmah, R. Y .2011. Gizi Kebugaran dan Olahraga, Lubuk Agung, Jawa Barat.

G Rancovic, V Mutavdzic, D Taskic, A Preljevic, M Kocic, GN Rancovic. 2010. Aerobic capacity as an indicator in different kinds of sports. Bosnian $J$ Of Basic Medical Sciences. 10(1):44-48.

Hasanatun, Srirahayu, E \& Agnesia, D .2019. "Hubungan Status Gizi dan Pengetahuan Gizi Seimbang dengan Kebugaran Jasmani pada Atlet Pencak Silat Pagar Nusa Gresik", Ghidza Media Journal, vol. 1, no. 1, hh: 1-9.

Hidayat, A., \& Suroto. 2017. Hubungan Antara Status Gizi Dan Aktivitas Fisik Dengan Tingkat Kebugaran Jasmani Siswa. Jurnal Pendidikan Olahraga Dan Kesehatan, 4(2), 516-521.

Kasyifa, I. N., Rahfiludin, M. Z., \& Suroto, S. 2018. Hubungan Status Gizi dan Aktivitas 
Istiqomah, I. P. N., Krisyanto, A. \& Ardyanto, T. D. Fisiomu.2022 Vol 3(1): 1-7 DOI : $10.23917 /$ fisiomu.v3i1.14802

fisik dengan Kebugaran Jasmani Remana. Medical Technology and Public Health Journal, 2(2),133-142.

Matsushigue, K. A., Hartmann, K., \& Franchini, E. 2009. Taekwondo: Physiological responses and match analysis. Journal of strength and conditioning research, 23(4), 1112-1117.

Mielgo-Ayuso, J., Maroto-Sánchez, B., Luzardo-Socorro, R., Palacios. 2015. Evaluation of nutritional status and energy expenditure in athletes. Nutricion hospitalaria, 31 Suppl 3, 227-236.

Rismayanthi C. 2012. Hubungan Antara Status Gizi dan Tingkat Kebugaran Jasmani. Jurnal Pendidikan. 42(1):29 - 38

Shete, A. N., Bute, S. S., \& Deshmukh, P. R. 2014. A Study of VO2 Max and Body Fat Percentage in Female Athletes. Journal of clinical and diagnostic research : JCDR, 8(12), BC01-BC3.

Peraturan Menteri Kesehatan Nomor 2 Tahun 2020. Standar Antropometri Anak.

Widiastuti. 2015. Tes dan Pengukuran Olahraga. Rajawali Press 
Istiqomah, I. P. N., Krisyanto, A. \& Ardyanto, T. D. Fisiomu.2022 Vol 3(1): 1-7

DOI : $10.23917 /$ fisiomu.v3i1.14802 